\title{
Other Caves Near the Ankarana Plateau
}

\subsection{Antsarahaso Maze}

A large karst area, the Analamera, extends northeast of the Ankarana Plateau. Recent exploration northeast of the Ankarana Plateau, led by the French caver J. C. Dobrilla, has indicated important speleological potential. He found an incredible maze, the Antsarahaso, whose length of $20 \mathrm{~km}$ makes it the third longest cave in Madagascar (Fig. 9.1).

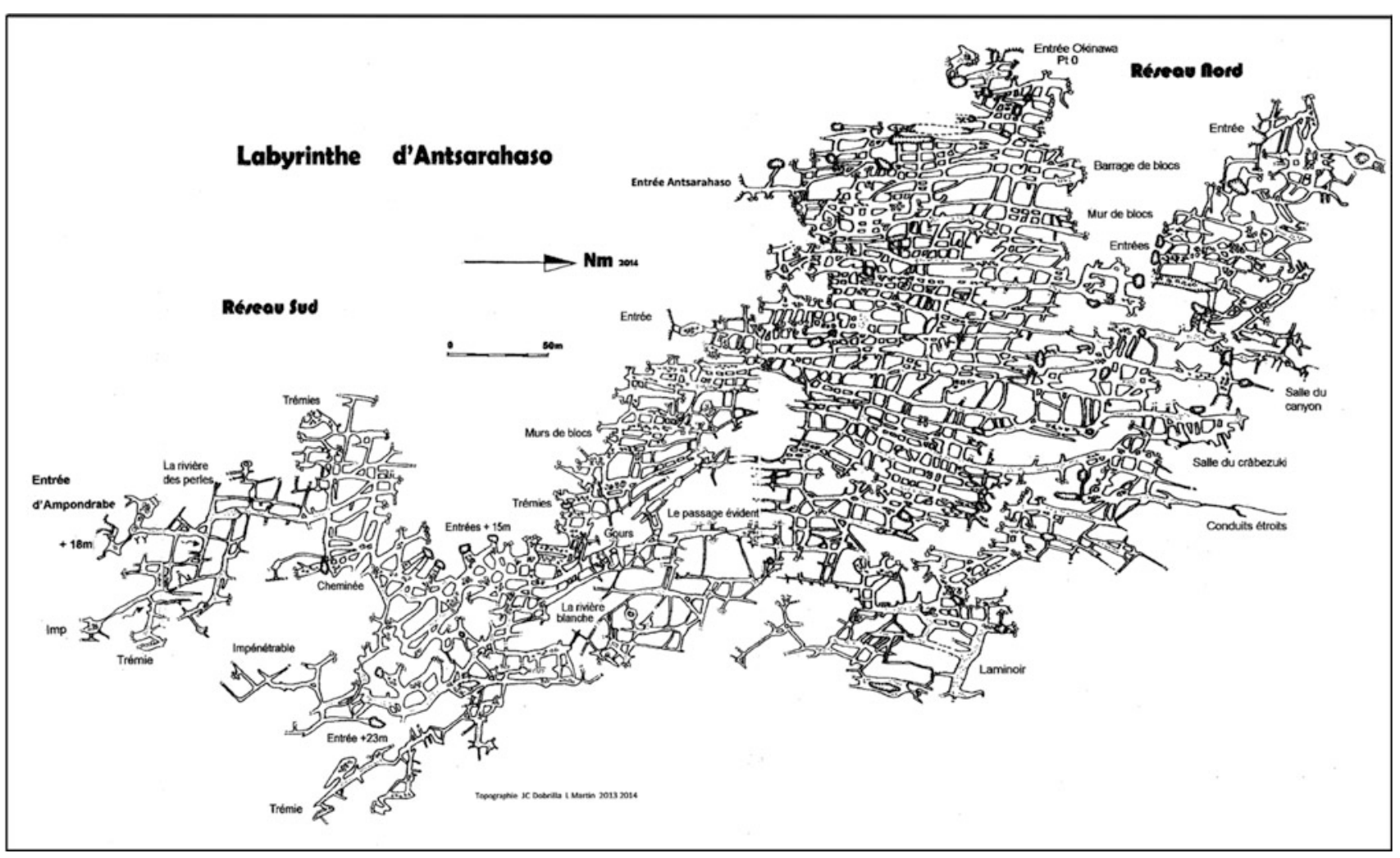

Fig. 9.1 The Antsarahaso maze (from Dobrilla) 